\author{
Д.Г. Румянцева', А.М. Лила', ${ }^{1,}$ Ш. Эрдес ${ }^{1}$
}

${ }^{1}$ ФГБНУ «Научноисследовательский институт ревматологии им. В.А. Насоновой» 115522, Российская Федерация, Москва, Каширское шоссе, 34 ФГБОУ ДПО «Российская медицинская академия непрерывного профессионального образования» Минздрава России 125993, Российская Федерация, Москва, ул. Баррикадная, 2/1, стр. 1

${ }^{1}$ V.A. Nasonova Research Institute of Rheumatology 115522, Russian Federation, Moscow, Kashirskoye Highway, $34 \mathrm{~A}$

${ }^{2}$ Russian Medical Academy of Continuous Professional Education of the Ministry of Healthcare of the Russian Federation

125993, Russian

Federation, Moscow,

Barrikadnaya str., 2/1, building 1

Контакты: Румянцева Дарья Гаврильевна, rumiantceva01@gmail. com

Contacts: Daria

Rumiantceva, rumiantceva01@gmail. com

Поступила 26.10.2020 Принята 13.11.2020
В период пандемии новой коронавирусной инфекции COVID-19 по всему миру резко возросла потребность в дистанционной связи между врачами и пациентами.

Цель - оценить возможности дистанционного взаимодействия между врачом-ревматологом и пациентами с использованием информационной технологии «ASpine» в условиях пандемии COVID-19.

Материал и методы. В рамках научного проекта использовалась информационная технология «ASpine», которая состоит из двух частей. Первая - непосредственно мобильное приложение для пациента с диагнозом аксиальный спондилоартрит и вторая - программа для персонального компьютера, которой пользуется врач-ревматолог для мониторинга состояния пациентов. В мобильном приложении «ASpine» пациенты заполняют опросники BASDAI, ASDAS-СРБ, BASFI, вносят данные различных исследований, контролируют выполнение ежедневных занятий лечебной физкультурой. Также в программе имеется возможность связаться с лечащим врачом посредством текстовых сообщений. В статье представлен опыт работы одного врача-ревматолога с информационной технологией «ASpine» в период пандемии COVID-19 с апреля по июнь 2020 г.

Результаты. С 1 января по 6 июня 2020 г. общее количество загрузок приложения «ASpine» из AppStore и GooglePlay составило 1778, больше всего скачиваний пришлось на время пандемии COVID-19. За этот период врач-ревматолог с помощью «АSpine» дистанционно наблюдал 71 пациента с аксиальным спондилоартритом. $47(66,1 \%)$ из них были прикреплены с апреля по июнь 2020 г. На 1 июня 2020 г. среднее значение

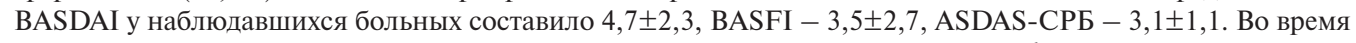
пандемии сообщения от пациентов приходили ежедневно в количестве от 1 до 16. Их рассмотрение и подготовка ответа врачом на одно обращение в среднем занимало 5 минут; обычно ежедневно на ответы требовалось не более 30 минут.

Заключение. Программа «ASpine» для пациентов с аксиальным спондилоартритом в период сложной обстановки в стране, обусловленной ограничительными мерами по профилактике COVID-19, оказала реальную помощь как альтернативный метод связи с лечащим врачом. В свою очередь, врачу ревматологу данная технология позволяет дистанционно мониторировать состояние здоровья большого числа пациентов при небольших затратах рабочего времени (не более 30 минут в день на 71 пациента).

Ключевые слова: телемедицина, мобильное приложение, коронавирусная инфекция, COVID-19, пандемия, аксиальный спондилоартрит, спондилоартрит, анкилозирующий спондилит

Для цитирования: Румянцева ДГ, Лила АМ, Эрдес Ш. Дистанционный мониторинг пациентов с аксиальным спондилоартритом в период пандемии COVID-19: результаты и перспективы использования информационной технологии «ASpine». Научно-практическая ревматология. 2020;58(6):683-690.

\section{REMOTE MONITORING OF PATIENTS WITH AXIAL SPONDYLOARTHRITIS DURING THE COVID-19 PANDEMIC: RESULTS AND PROSPECTS OF USING THE INFORMATION TECHNOLOGY “ASPINE"}

\author{
Daria G. Rumiantceva ${ }^{1}$, Aleksander M. Lila ${ }^{1,2}$, Shandor Erdes $^{1}$
}

During the pandemic of the new coronavirus infection COVID-19, the need for remote communication between doctors and patients has increased around the world.

Objective: remote interaction between rheumatologist and patients using "ASpine" technology in the context of the COVID-19 pandemic.

Subjects and methods. Within the framework of the scientific project, the information technology "ASpine" was used, which consists of two parts. The first is directly a mobile application for patients with a diagnosis of axial spondyloarthritis and the second is a program for a personal computer that is used by a rheumatologist. In the "ASpine" application, patients fill out BASDAI, ASDAS-CRP, BASFI questionnaires, enter data from various studies, and control the performance of daily exercise therapy. Also, the program has the ability to contact the attending physician via text messages.

The paper presents the experience of one rheumatologist with the information technology "ASpine" during the COVID-19 pandemic from April to June 2020.

Results. From January 1 to June 6, 2020, the total number of downloads of "ASpine" applications from the AppStore and GooglePlay was 1778, most of all during the COVID-19 pandemic. During this period, a rheumatologist using "ASpine" remotely observed 71 patients with axial spondyloarthritis. 47 (66.1\%) of them were attached from April to June 2020. As of June 1, 2020, the average BASDAI in the observed values of patients was $4.7 \pm 2.3$, BASFI $3.5 \pm 2.7$, ASDAS-CRP $-3.1 \pm 1.1$. During a pandemic, messages from patients came in daily from 1 to 16 . Their review and preparation of a response by a doctor per call took an average of 5 minutes; usually it took no more than 30 minutes to answer each day. 
Conclusion. The "ASpine" program for patients with axial spondyloarthritis during a difficult situation in the country caused by restrictive means of preventing COVID-19 provided real help as an alternative method of communication with the attending physician. In turn, the technology allows a rheumatologist to remotely monitor the health status of a large number of time expenditures (no more than 30 minutes per day for 71 patients). Keywords: telemedicine, mobile application, coronavirus infection, COVID-19, pandemic, axial spondyloarthritis, spondyloarthritis, ankylosing spondylitis

For citation: Rumiantceva DG, Lila AM, Erdes S. Remote monitoring of patients with axial spondyloarthritis during the COVID-19 pandemic: results and prospects of using the information technology "ASpine". Nauchcno-Practicheskaya Revmatologia = Rheumatology Science and Practice 2020;58(6):683-690 (In Russ.).

doi: $10.47360 / 1995-4484-2020-683-690$

«Целью Глобальной стратегии Всемирной организации здравоохранения (ВО3) 2020-2024 гг. в области цифрового здравоохранения является пропаганда здорового образа жизни и благополучия для всех, везде, в любом возрасте» [1]. Для реализации своего потенциала национальные или региональные инициативы в области цифрового здравоохранения должны опираться на надежную стратегию, которая объединяет финансовые, организационные, людские и технологические ресурсы. ВОЗ будет уделять основное внимание предоставлению странам возможности планировать, внедрять и улучшать безопасные технологии, которые обеспечат достижение данной цели для улучшения здоровья и благополучия всех слоев населения вне зависимости от места проживания.

В Российской Федерации (РФ) с 1 января 2018 г. вступил в силу федеральный закон (Ф3) о телемедицине (№ 242-Ф3 «О внесении изменений в отдельные законодательные акты РФ по вопросам применения информационных технологий в сфере здравоохранения»), благодаря которому пациенты могут получать медицинскую помощь дистанционно посредством телемедицинских консультаций. В настоящее время существует несколько определений телемедицины. Согласно определению ВО3, телемедицина - это предоставление услуг здравоохранения в условиях, когда расстояние является критическим фактором с использованием информационно-коммуникационных технологий для обмена необходимой информацией в целях диагностики, лечения и профилактики заболеваний и травм, проведения исследований и оценок, а также для непрерывного образования медицинских работников в интересах улучшения здоровья населения и развития местных сообществ [2].

Ф3 № 242 от 29.06.17 г. дополнил Статью 2 Ф3 № 323 пунктом 22, который определяет телемедицинские технологии как информационные технологии, обеспечивающие дистанционное взаимодействие медицинских работников между собой, с пациентами и/или их законными представителями, идентификацию и аутентификацию указанных лиц, документирование совершаемых ими действий при проведении консилиумов, консультаций, дистанционного медицинского наблюдения за состоянием здоровья пациента. Таким образом, телемедицина - это не отдельный вид медицинской деятельности, а технология, которая используется при осуществлении медицинской деятельности.

Американский венчурный фонд Rock Health опубликовал отчет, в котором утверждает, что инвестиции в сфере информационных технологий в здравоохранении в первом квартале этого года удвоились по сравнению с аналогичным периодом прошлого года. По данным фонда, инвестиции в стартапы в сфере цифрового здравоохранения в США с января по март этого года составили 3,1 млрд долларов. Это почти в два раза больше, чем за аналогичный период прошлого года, и почти половина от общего годового объема в 7,4 млрд долларов [3]. Стартапы в сфере цифрового здравоохранения в Европе с 2015 г. привлекли почти 7 млрд долларов более чем в 1300 сделках. Несмотря на то, что компании США по-прежнему представляют большую часть рынка цифрового здравоохранения, 2019 г. стал рекордным по финансированию и сделкам для стартапов в этой сфере в Европе, что составило около 2,4 млрд долларов более чем в 300 сделках. Российская компания $\mathrm{DOC}+$, представляющая услуги онлайн-консультирования врачами разных специальностей, находится на 12-м месте среди европейских компаний по объему инвестиций на 2020 г. (21 млрд долларов) [4].

Наиболее активное развитие телемедицина в РФ и мире получила в 2020 г. во время пандемии новой коронавирусной инфекции COVID-19, когда традиционные услуги здравоохранения стали труднодоступны для широких слоев населения из-за ограничительных мер. 22 марта 2020 г. в связи с распространением коронавирусной инфекции на официальном сайте Минздрава РФ во вкладке «новости» были опубликованы рекомендации пациентам, страдающим аутоиммунными заболеваниями и получающим иммуносупрессивную терапию. Им предложено соблюдать меры предосторожности, чтобы снизить риск заражения: «для этого рекомендовано временно ограничить контакты с другими людьми, пользование общественным транспортом, посещение общественных мест, таких как торговые центры и магазины, поликлиники и др.» [5]. В то же время по всей стране большинство ревматологических стационаров были перепрофилированы на время пандемии, а амбулаторные приемы специалистов ограничены. Вместе с тем, согласно международным и российским рекомендациям по ведению пациентов с ревматическими заболеваниями, активный мониторинг и своевременная коррекция терапии позволяют сохранить качество жизни и предупредить развитие необратимых изменений. Для некоторых пациентов промежуток времени в 2-3 месяца без помощи профильного специалиста ревматолога может привести к жизнеугрожающим состояниям. Поэтому дистанционный мониторинг хронических заболеваний в настоящее время становится все более актуальным.

В свою очередь, парламентом РФ был предложен ряд поправок к закону «Об основах охраны здоровья граждан». Данный законопроект предусматривает возможность оказания медицинской помощи, в том числе с применением телемедицинских технологий при чрезвычайных ситуациях или угрозе распространения опасного заболевания. Сейчас он находится на рассмотрении Государственной думы РФ в первом чтении [6].

Также внесены важные поправки к законопроекту «Об экспериментальных правовых режимах в сфере цифровых инноваций», принятому 12.05.2020 г. Госдумой РФ в первом чтении [7]. Предлагается ввести особый порядок определения тарифов обязательного медицинского страхования (ОМС) для телемедицинских консультаций и других цифровых решений в здравоохранении [7]. Эта поправка 
позволит оплачивать из средств фонда ОМС телемедицинскую помощь и работу систем поддержки принятия врачебных решений.

По мнению аналитиков, технологии бесконтактного мониторинга пациентов тяготеют к использованию видео, звукового анализа и мобильных платформ, включающих передовые технологии, такие как машинное обучение и алгоритмы искусственного интеллекта. Поэтому рынок цифровой медицины динамично растет. По данным Global Market Insights, объем мирового рынка к 2025 г. увеличится более чем в 5 раз и достигнет 504,4 млрд долларов, тогда как в 2018 г. данный показатель составлял 86,4 млрд долларов.

В настоящее время, в связи с развитием информационно-коммуникационных технологий и мобильных систем связи, есть возможность проводить и развивать дистанционный мониторинг состояния пациентов, находящихся на длительной терапии.

Аксиальный спондилоартрит (аксСпА) - это хроническое воспалительное ревматическое заболевание, которое поражает преимущественно позвоночник и крестцово-подвздошные суставы, нарушая их функцию, и значительно снижая качество жизни. Пациенты с аксСпА могут быть кандидатами на использование мобильных технологий в здравоохранении. Дебют аксСпА приходится на молодой возраст (приблизительно от 20 до 35 лет) [8], когда больные обычно могут быстро освоить новые технологии и устройства [9]. Согласно исследованию E. Mollard и К. Michaud [10], 90\% людей почти всегда держат свои мобильные устройства возле себя [10]. Кроме того, люди, страдающие аксСпА, очень обеспокоены влиянием заболевания на жизненный прогноз. Поскольку пациенты должны следить за состоянием своего здоровья постоянно, мобильные приложения и программы могут им помогать в вопросах самоконтроля, мотивационной поддержки, медицинского информационного образования и приверженности лечению. Портативность мобильных устройств (смартфонов) потенциально может служить благоприятным фактором, обеспечивающим возможность долгосрочного наблюдения и содействия оказанию медицинской помощи дистанционно из любой точки мира.

В 2017 г. была опубликована история создания, описание технической составляющей и предварительные результаты тестирования мобильного приложения «ASpine», совместной разработки ФГБНУ НИИР им. В.А. Насоновой и Межрегиональной общественной благотворительной организации инвалидов «Общество взаимопомощи при болезни Бехтерева» (МРОБОИ «ОВББ») [11]. В настоящее время в мире до сих пор нет доступных аналогов мобильных приложений «ASpine», которые бы позволили врачамревматологам дистанционно мониторировать состояние здоровья больных аксСпА, а пациентам - контактировать с лечащим врачом [12]. В период пандемии новой коронавирусной инфекции COVID-19 использование программы «ASpine» стало еще более актуальным.

Целью работы была оценка возможности дистанционной взаимосвязи между врачом-ревматологом и пациентами с использованием информационной технологии «ASpine» в период пандемии COVID-19.

\section{Материал и методы}

Мобильное приложение «ASpine» имеется в свободном доступе, пациенты с аксСпА могут скачать его на свои мобильные устройства из Play Market, AppStore и использовать как инструмент самоконтроля за состоянием здоровья.

В рамках нашего научного проекта к мобильному приложению была добавлена программа для персонального компьютера (ПК), которой пользуется врач-ревматолог для мониторинга состояния пациентов. В программе также имеется возможность дистанционной связи между врачом и пациентом. Скачав приложение «ASpine», пациент имел возможность «прикрепиться» к лечащему врачу, участвовавшему в данном научном проекте, на очном визите после установления диагноза аксСпА и подписания информированного согласия. У пациента и врача была возможность обмена информацией. Все данные о пациенте строго конфиденциальны и доступны только его лечащему врачу.

Администратор проекта регистрировал в программе для ПК врачей-ревматологов, участвовавших в апробации информационной технологии «ASpine», и их пациентов (рис. 1).

Согласно Ф3 № 242-Ф3 «О внесении изменений в отдельные законодательные акты РФ по вопросам применения информационных технологий в сфере здравоохранения», в рамках организации и оказания медицинской помощи с применением телемедицинских технологий существует дистанционное взаимодействие медицинских работников между собой и с пациентами и/или их законными представителями. Медицинские работники могут взаимодействовать с пациентами посредством видеоконсультаций, аудиосвязи, обмена текстовыми сообщениями и файлами.

Дистанционное взаимодействие врачей между собой в программе «ASpine» происходит только при условии, что администратор «прикрепляет» пациентов к врачу-ревматологу, при этом он не имеет возможности видеть персональные данные больных. Взаимодействие врача-ревматолога с пациентом подразумевает доступ лечащего врача к информации о состоянии здоровья больного, обмен текстовыми сообщениями и файлами.

Мобильное приложение «ASpine» предназначено для пациентов с аксСпА и построено на выполнении ими определенных задач, которые позволяют максимально оптимизировать лечебный процесс (рис. 2). Это достигается посредством регулярного заполнения опросников BASDAI (Bath Ankylosing Spondylitis Disease Activity Index), ASDAS-CРБ (Ankylosing Spondylitis Disease Activity Score C-pеактивный белок) и BASFI (Bath Ankylosing Spondylitis Functional Index), внесения данных различных исследований, автоматических напоминаний о необходимости приема лекарственных препаратов, ежедневных занятий лечебной физкультурой (ЛФК) и возможности связаться с лечащим врачом посредством текстовых сообщений. Пользователь может самостоятельно выбирать частоту напоминаний о той или иной задаче в календаре и получать за выполненное задание «баллы здоровья» для большей мотивации.

При регистрации пользователя в приложении «ASpine» соблюдены все юридические нормы о локализации хранения и отдельных процессов обработки персональных данных, определенные в Ф3 № 242 от 21 июля 2014 г. «О внесении изменений в отдельные законодательные акты РФ в части уточнения порядка обработки персональных данных в информационно-телекоммуникационных сетях» и необходимости добровольного информированного согласия в соответствии с требованиями законодательства РФ. 


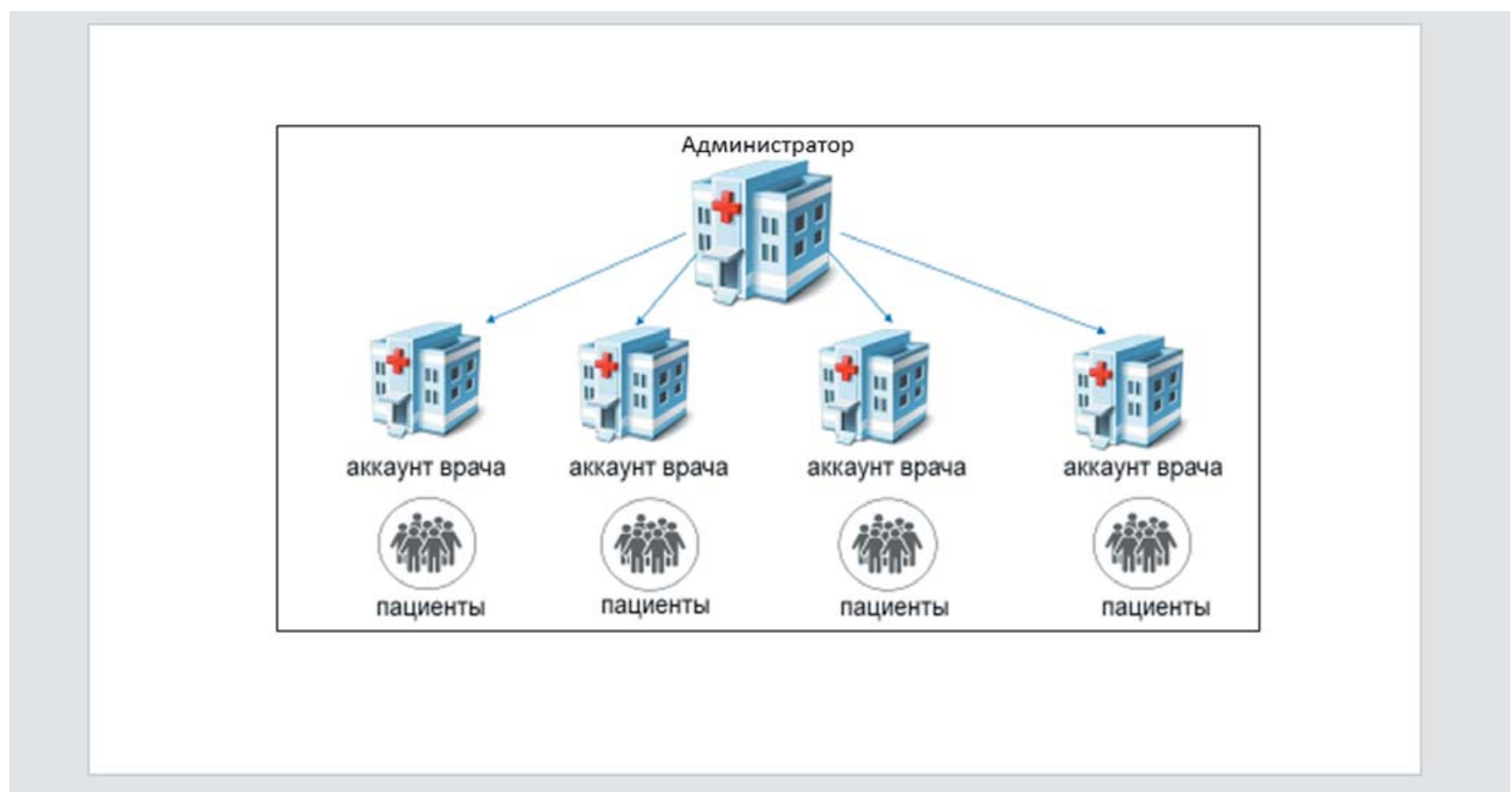

Рис. 1. Структура программы «ASpine»



Pис. 2. Примеры интерфейсов с отображением динамики индексов BASDAI, BASFI в приложении «ASpine»

Индексы BASDAI и ASDAS-СРБ позволяют оценить клиническую активность аксСпА, BASFI отражает функциональный статус пациента. Соответствующие опросники заполняются пациентами согласно рекомендациям Ассоциации ревматологов России и ASAS [13, 14]. В начале использования приложения независимо от активности заболевания пациенту еженедельно приходят уведомления о необходимости заполнения опросников BASDAI, ASDAS-СРБ, BASFI. В дальнейшем он имеет возможность самостоятельно регулировать частоту заполнения опросников. Однако при значении индекса BASDAI $\geqslant 4$ и/или ASDAS-СРБ $\geqslant 2,1$, система оповещает пациента о том, что у него увеличилась степень активности заболевания и требуется еженедельное заполнение опросников, а также консультация лечащего врача. Одновременно приложение посылает оповещение об ухудшении состояния данного пациента его лечащему врачу. Помимо этого пациенты могут вносить в систему данные инструментальных и лабораторных исследований. Они также дают возможность врачу контролировать лекарственную терапию, внося данные о дозе и частоте приема препаратов и могут просматривать видео с уроками ЛФК.

При обострении заболевания или появлении новых симптомов, например, впервые возникшей боли в суставе, или неблагоприятной реакции на препарат у пациента есть возможность сообщить об этом своему врачу. Далее открывается диалоговое окно, которое позволяет врачу отправить комментарий либо пригласить пациента на очный прием. 


\section{Результаты}

Всего за период с 1 января по 6 июня 2020 г. мобильное приложение «ASpine» было установлено 1778 раз, из них 1265 - из Play Market и 513 - из AppStore. Больше всего скачиваний пришлось на период пандемии COVID-19, особенно на май 2020 г. В подавляющем большинстве случаев мобильное приложение «ASpine» скачивали пользователи, находившиеся в России, а также на Украине, в США и в Казахстане.

Всего в системе «ASpine» было зарегистрировано 10 ревматологов, в том числе 3 сотрудника ФГБНУ НИИР им. В.А. Насоновой (Москва), 5 врачей из Республики Саха (Якутия) (Якутск) и 2 - из Санкт-Петербурга. В данной статье мы подробнее рассмотрим работу одного врачаревматолога ФГБНУ НИИР им. В.А. Насоновой в рамках научного проекта в условиях пандемии COVID-19 с апреля по июнь 2020 г.

В целом у данного специалиста за весь период работы с технологией «ASpine» дистанционно наблюдался 71 пациент с аксСпА. 47 (66,1\%) из этих больных были прикреплены в период пандемии с апреля по июнь 2020 г. Средний возраст пациентов составил $37,4 \pm 9,5$ года. Среди них было 42,3\% мужчин и 57,7\% женщин. $47(66,1 \%)$ больных были позитивны по HLA-B27.

На 1 июня 2020 г. среднее значение BASDAI у наблю-

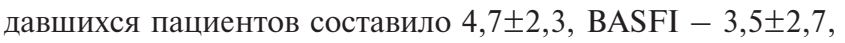

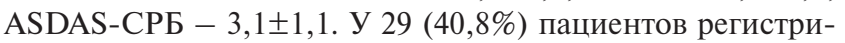
ровалась высокая активность аксСпА (BASDAI $\geqslant 4$ и/или ASDAS-СРБ $\geqslant 2,1)$.

На главном экране программы «ASpine» у лечащего врача (рис. 3) отображается список всех прикрепленных к нему пациентов с информацией об активности заболевания.

Во время пандемии сообщения от пациентов приходили ежедневно в количестве от 1 до 16, в том числе один пользователь мог отправить несколько сообщений. В среднем ежедневно 3-4 человека присылали различные вопросы. В первую очередь, они касались организационных проблем во время пандемии COVID-19, например, необходима ли в данный момент пациенту госпитализация или очный прием ревматолога и куда можно обратиться. Рассмотрение и ответ у врача занимали в среднем 5 минут, то есть затрачивалось ежедневно не более 30 минут рабочего времени на ответы пациентам. При необходимости врач мог зайти на персональную страницу пациента и оценить динамику активности заболевания, функционального статуса, назначенную терапию, результаты клинических анализов и задания, которые пользователь установил для самоконтроля (рис. 4).

Таким образом, дистанционная работа врача-ревматолога с 71 пациентом в информационной технологии «ASpine» в период пандемии COVID-19 показала свою эффективность. Программа «ASpine» для пациентов с аксСпА в сложный период пандемии была востребована и оказала реальную помощь как альтернативный метод взаимодействия лечащего врача с пациентом. Данная технология позволяет дистанционно мониторировать состояние здоровья большого количества больных при небольших затратах рабочего времени.

\section{Обсуждение}

Проблемы, с которыми столкнулось современное здравоохранение всего мира в 2020 г. во время пандемии COVID-19, показали необходимость развития и внедрения новых альтернативных способов взаимодействия пациентов с врачами. Телемедицина может стать эффективным инструментом для выполнения поставленных задач. Резкое увеличение количества загрузок мобильного приложения

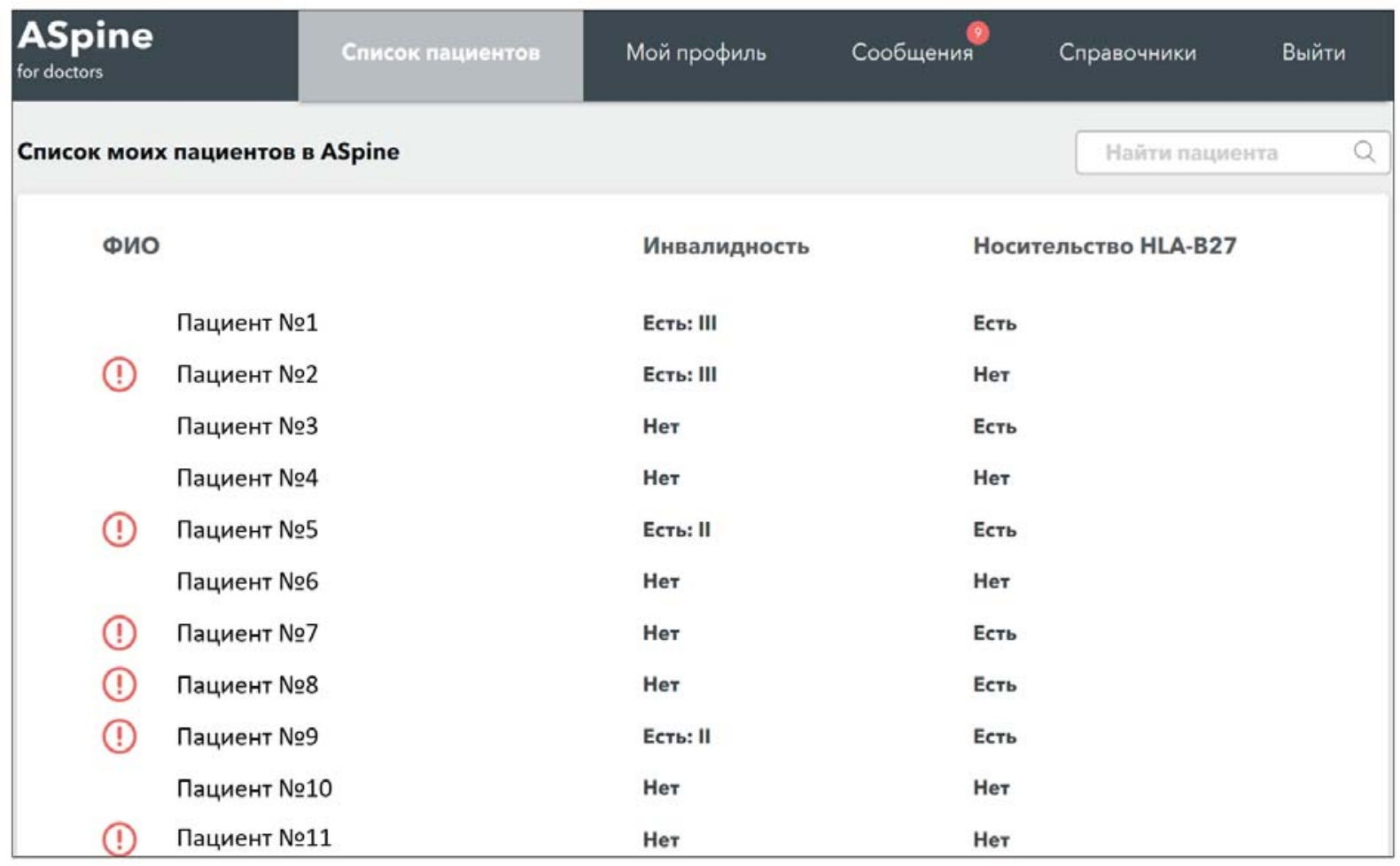

Рис. 3. Главный экран с перечнем всех пациентов лечащего врача ревматолога 


\section{Медицинские данные}

Инвалидность

Нет

Аллергические реакции на лекарства

Нет

Сопутствующие установленные заболевания Heт

Наследственность по ревматическим болезням Heт

Носительство HLA-B27

Есть

\section{Упражнения для низк. активности}

Периодичность: Ежедневно

Выполнено 2020-06-08 11:59:06

ПОДРОБНЕЕ

\section{Анализ крови}

Периодичность: 1 раз в 3 месяца

Выполнено 2020-05-18 12:20:52

\section{ПОДРОБНЕE}

Последние результаты прохождения тестов
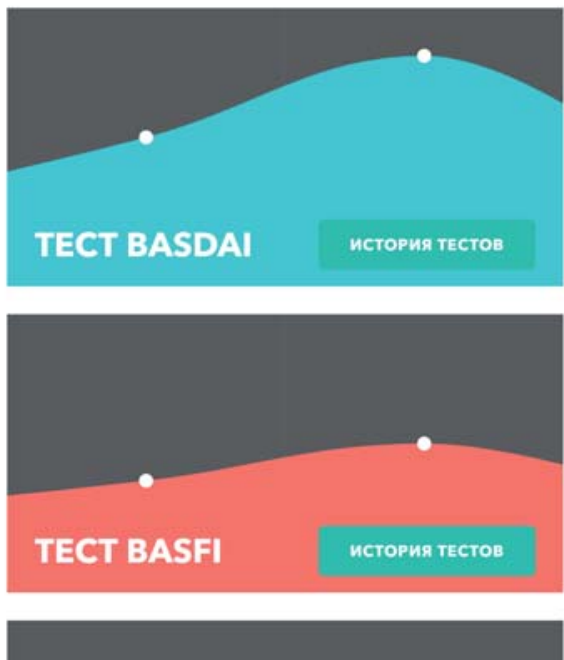

A

\section{Диаскинтест}

Периодичность: 1 раз в полгода

Выполнено 2020-05-18 12:25:44

\section{ПОДРОБНЕЕ}

\section{Рентген}

Периодичность: 1 раз в год

Выполнено 2020-05-18 12:26:57

\section{ПОДРОБНЕЕ}

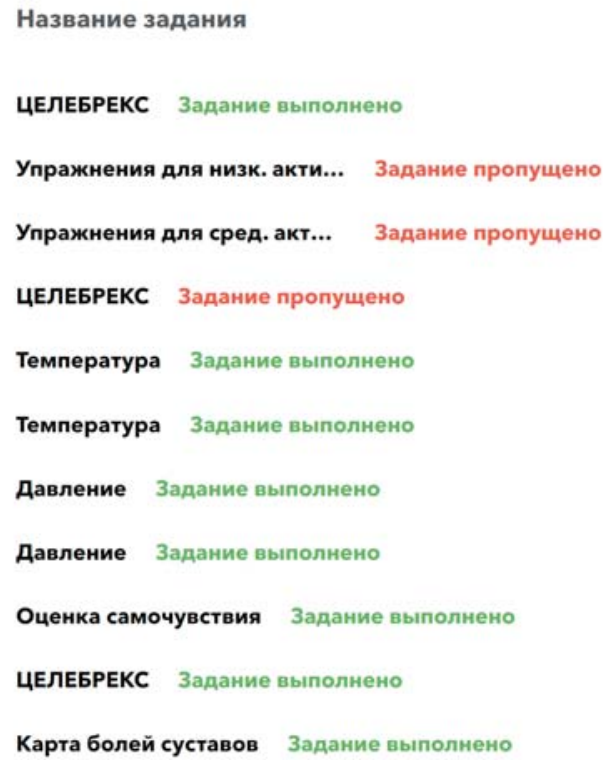

Дата и время

26.05.2020, 16:12

24.05.2020, 23:59

$24.05 .2020,23: 59$

24.05.2020, 18:00

24.05.2020, 22:36

24.05.2020, 22:36

24.05.2020, 22:35

24.05.2020, 22:35

24.05.2020, 22:34

24.05.2020, 22:32

24.05.2020, 22:27

Рис. 4. Пример персональной страницы пациента с аксСпА в программе для ПК лечащего врача ревматолога. А - основная страница, Б задания, которые пациент себе установил, $B$ - история выполнения всех заданий 
«ASpine» в период пандемии COVID-19 подтверждает потребность пациентов с хроническими ревматическими заболеваниями в активном самоконтроле и дистанционном наблюдении профильного специалиста. Работа с приложением «ASpine» за пределами РФ также указывает на востребованность данной технологии, предположительно в связи с трудностями получения пациентами специализированной помощи. Учитывая распространенность анкилозирующего спондилита, которая составляет 0,1 на 100 тыс. населения [15], за последние несколько месяцев примерно каждый пятидесятый пациент в России установил себе приложение «ASpine».

Вовлечение пациентов в контроль за своим состоянием здоровья с помощью мобильного приложения имеет важное значение в улучшении приверженности лечению и может способствовать уменьшению активности заболевания и количества очных посещений профильных специалистов. По данным заполнения опросников BASDAI и ASDAS-CРБ в приложении «ASpine», в период пандемии COVID-19 почти половина пациентов находились в обострении, что подчеркивает важность дистанционного мониторинга. Одной из причин высокой активности болезни может быть резкое ограничение возможности проведения очных консультаций и стационарного лечения в профильных отделениях, а иногда и приостановление терапии, в том числе генно-инженерными биологическими препаратами.

Анализируя работу врача-ревматолога с сообщениями, можно сделать вывод, что данное взаимодействие значительно сокращает экономические потери как со стороны системы здравоохранения, так и со стороны пациентов. Врач может дистанционно следить за динамикой состояния больного и выполнением данных им рекомендаций, не заполняя при этом многочисленные медицинские документы. Кроме того, уменьшается нагрузка на амбулаторную сеть и расходы пациентов на транспортные услуги, потому что большинство вопросов можно быстро решить дистанционно, не приходя на очный визит к доктору.

Телемедицина по сути это технология, позволяющая оказывать медицинскую помощь на расстоянии, в которую входят дистанционный мониторинг врачом пациентов и онлайн-консультация. Есть две основные системы, где по защищенным каналам можно передавать персональные данные и осуществлять телемедицинские консультации: федеральная телемедицинская информационная система и единая государственная информационная система в сфере здравоохранения (ЕГИСЗ). Оказание телемедицинских услуг осуществляется за счет средств ОМС на основе точечных тарифных соглашений, формируемых на региональном уровне территориальными фондами ОМС, органами власти регионов и страховыми организациями. Также проведение телемедицинских консультаций возможно за счет добровольного медицинского страхования и личных средств пациентов. Поэтому уже в ближайшем будущем прогнозируется увеличение количества различных телемедицинских технологий как в частном, так и в государственном секторе лечебно-профилактических учреждений.

Похожая система мониторинга пациентов с AC «Smart-phone SpondyloArthritis Management System
(SpAMS)» реализуется в Китае с помощью мобильного приложения для передачи текстовых и голосовых сообщений «Wechat» [16]. Работа в «SpAMS» основана также на дистанционном мониторинге врачами-ревматологами пациентов с анкилозирующим спондилитом и при необходимости позволяет вызывать их на очные консультации. Главное отличие системы заключается в том, что «SpAMS» работает только на основе приложения «Wechat» и только в Китае, тогда как технология «ASpine» более универсальна и может быть внедрена во многих странах.

\section{Заключение}

Таким образом, технологическая революция в здравоохранении продолжается, и пандемия COVID-19 явилась лишь катализатором в осознании медицинским сообществом необходимости внедрения телемедицинских мобильных инноваций в реальную клиническую практику. Однако, к сожалению, пока мало специалистов, которые обладают необходимыми знаниями одновременно в области медицины и в области цифровых технологий. По-прежнему существуют проблемы с оцифровкой медицинских данных и их извлечением из носителей, трансформацией рутинной клинической деятельности в онлайн-системы и наоборот. Но с принятием поправок в законодательстве по проведению телемедицинских консультаций у нас открываются перспективы развития цифрового здравоохранения, в том числе и в области ревматологии.

\section{Прозрачность исследования}

Исследование не имело спонсорской поддержки. Авторы несут полную ответственность за предоставление окончательной версии рукописи в печать.

Декларация о финансовых и других взаимоотношениях

Все авторы принимали участие в разработке концепции статьи и в написании рукописи. Окончательная версия рукописи была одобрена всеми авторами. Авторы не получали гонорар за статью.

Исследование выполнено в рамках поисковой темы «Разработка методов диагностики и дистанционного мониторинга поражения осевого скелета при анкилозирующем спондилите и псориатическом артрите», номер темы НИОКР АААA-A20-120041490010-4.

Авторы выражают благодарность за помощь в создании и поддержке мобильного приложения «ASpine» председателю некоммерческой организации «ОВББ» Алексею Ситало, сотруднику ООО «Мастер алгоритмов» Михаилу Дудареву, компании ООО «НовоТех»: Александру Демченко (исполнительному директору, руководителю проекта), Александру Гарматенко (техническому директору), Жанне Кравченко (проект-менеджеру), Антону Порошину (ведущему разработчику системы управления и АРI), Максиму Петренко (разработчику системы управления и АРI), Алексею Дячек (разработчику мобильного приложения), Людмиле Николаенко (разработчику системы управления), Валентину Дроздову (дизайнеру), Дарье Пишта (ведущемудизайнеру приложения). 


\section{Л И T E Р А У PA / REFERE N C E S}

1. WHO. Digtal health. URL: https://www.brenda-enzymes.org/ enzyme.php?ecno=2.3.1.54 (Date accessed: 2020).

2. WHO. A health telematics policy in support of WHO's HealthFor-All strategy for global health development: report of the WHO group consultation on health telematics, 11-16 December, Geneva, 1997. Geneva, World Health Organization, 1998.

3. Инвестиции в цифровую медицину США удвоились. [US digital medicine investment doubles (In Russ.)]. URL: https://evercare.ru/news/investicii-v-cifrovuyu-medicinu-v-ssha-udvoilis (Date accessed: 2020).

4. Самые хорошо финансируемые цифровые стартапы в области здравоохранения в Европе. [Best funded digital healthcare startups in Europe (In Russ.)]. URL: https://evercare.ru/news/ samye-khorosho-finansiruemye-cifrovye-startapy-v-oblasti-zdravookhraneniya-v-evrope (Date accessed: 2020).

5. Министерство здравоохранения РФ. Информация для пациентов, получающих иммуносупрессивную и химиотерапию. [Ministry of Health of the Russian Federation. Information for patients receiving immunosuppressive drugs and chemotherapy (In Russ.)]. URL: https://www.rosminzdrav.ru/ news/2020/03/22/13562-informatsiya-dlya-patsientov-poluchayuschih-immunosupressivnuyu-i-himioterapiyu (Date accessed: 2020)

6. Система обеспечения законодательной деятельности. Законопроект № 930215-7 «О внесении изменений в Федеральный закон «Об основах охраны здоровья граждан в Российской Федерации» (в части особенностей оказания медицинской помощи в условиях чрезвычайных ситуаций). [Legislative support system. Bill No. 930215-7 On Amendments to the Federal Law "On the fundamentals of health protection of citizens in the Russian Federation" (regarding the peculiarities of providing medical care in emergency situations) (In Russ.)] URL: http://sozd.duma.gov.ru/bill/930215-7\#bh_histras (Date accessed: 2020).

7. Система обеспечения законодательной деятельности. Законопроект № 922869-7 «Об экспериментальных правовых режимах в сфере цифровых инноваций в Российской Федерации». [Legislative support system. Draft Law No. 9228697 "On Experimental Legal Regimes in the Field of Digital Innovation in the Russian Federation.” (In Russ.)]. URL: https:// sozd.duma.gov.ru/bill/922869-7 (Date accessed: 2020).

8. Румянцева ДГ, Дубинина ТВ, Демина АБ, и др. Анкилозирующий спондилит и нерентгенологический аксиальный спондилоартрит: две стадии одной болезни? Терапевтический архив. 2017;89(5):33-37. [Rumiantceva DG,
Dubinina TV, Demina AB, et al. Ankylosing spondylitis and non-radiological axial spondyloarthritis: two stages of one disease? Terapevticheskii arhiv. 2017;89(5):33-37 (In Russ.)]. DOI: 10.17116/terarkh201789533-37

9. Sawyer SM, Afifi RA, Bearinger LH, et al. Adolescence: A foundation for future health. Lancet. 2012;379(9826):16301640. DOI: 10.1016/S0140-6736(12)60072-5

10. Mollard E, Michaud K. Mobile apps for rheumatoid arthritis: opportunities and challenges. Rheum Dis Clin N Am. 2019;45(2):197-209. DOI: 10.1016/j.rdc.2019.01.011

11. Румянцева ДГ, Дубинина ТВ, Эрдес ШФ. Проект мобильного приложения «ASpine» для пациентов с ранним аксиальным спондилоартритом. Научно-практическая ревматология. 2017;55(6):621-627. [Rumiantceva DG, Dubinina TV, Erdes SF. Draft «ASpine» mobile application for patients with early axial spondyloarthritis. Nauchnoprakticheskaya revmatologiya $=$ Rheumatology Science and Practice. 2017;55(6):621-627 (In Russ.)]. DOI: 10.14412/1995-4484-2017-621-627

12. My health apps. URL: http://myhealthapps.net/ (Date accessed: 2020).

13. Дубинина ТВ, Гайдукова ИЗ, Годзенко АА, и др. Рекомендации по оценке активности болезни и функционального состояния больных анкилозирующим спондилитом в клинической практике. Научно-практическая ревматология. 2017;55(4):344-350. [Dubinina TV, Gaidukova IZ, Godzenko AA, et al. Guidelines for the assessment of disease activity and functional status in patients with ankylosing spondylitis in clinical practice. Nauchnoprakticheskaya revmatologiya $=$ Rheumatology Science and Practice. 2017;55(4):344-350 (In Russ.)]. DOI: 10.14412/1995-4484-2017-344-350

14. Sieper J, Rudwaleit M, Baraliakos X, et al. The Assessment of SpondyloArthritis international Society (ASAS) handbook: A guide to assess spondyloarthritis. Ann Rheum Dis. 2009;68(2):ii1-ii44. DOI: 10.1136/ard.2008.104018

15. Галушко ЕА, Насонов ЕЛ. Распространенность ревматических заболеваний в России. Альманах клинической медицины. 2018;46(1):32-39. [Galushko EA, Nasonov EL. Prevalence of rheumatic diseases in Russia. Almanac of Clinical Medicine. 2018;46(1):32-39 (In Russ.)]. DOI: 10.18786/2072-0505-2018-461-32-39

16. Ji X, Wang Y, Ma Y, et al. Improvement of disease management and cost effectiveness in Chinese patients with ankylosing spondylitis using a smart-phone management system: A prospective cohort study. Biomed Res Int. 2019;2019:2171475. DOI: $10.1155 / 2019 / 2171475$

Румянцева Д.Г. ORCID: https://orcid.org/0000-0002-1684-1213

Лила A.M. ORCID: https://orcid.org/0000-0002-6068-3080

Эрдес Ш. ORCID: https://orcid.org/0000-0003-3195-5187 